\title{
Coated expandable metal stents are effective irrespective of airway pathology
}

\author{
Cecilia Menna ${ }^{1}$, Camilla Poggi ${ }^{1}$, Mohsen Ibrahim ${ }^{1}$, Antonio D’Andrilli ${ }^{1}$, Anna Maria Ciccone ${ }^{1}$, Giulio \\ Maurizi $^{1}$, Francesco Cassiano ${ }^{1}$, Alberto E. Baccarini ${ }^{1}$, Domenico Massullo ${ }^{2}$, Federico Venuta ${ }^{3,4}$, Erino A. \\ Rendina ${ }^{1,4}$, Claudio Andreetti ${ }^{1}$ \\ ${ }^{1}$ Division of Thoracic Surgery, ${ }^{2}$ Division of Anaesthesiology, Sant'Andrea Hospital, University of Rome "Sapienza", Rome, Italy; ${ }^{3}$ Division of \\ Thoracic Surgery, Policlinico Umberto I Hospital, University of Rome "Sapienza”, Rome, Italy; ${ }^{4}$ Fondazione Cenci-Lorillard, Rome, Italy \\ Contributions: (I) Conception and design: C Andreetti, C Menna, C Poggi; (II) Administrative support: AE Baccarini; (III) Provision of study materials \\ or patients: F Cassiano, AM Ciccone, A D'Andrilli, G Maurizi; (IV) Collection and assembly of data: M Ibrahim, D Massullo; (V) Data analysis and \\ interpretation: C Menna, F Venuta, EA Rendina, C Andreetti; (VI) Manuscript writing: All authors; (VII) Final approval of manuscript: All authors. \\ Correspondence to: Camilla Poggi. Division of Thoracic Surgery, Sant'Andrea Hospital, University of Rome "Sapienza”, Via di Grottarossa 1035, \\ 00189 Rome, Italy. Email: camillapoggi@gmail.com.
}

Background: Tracheobronchial stents are a treatment option for inoperable benign or malignant tracheobronchial stenosis (TBS) or postoperative bronchopleural fistulas (POBPF). The present study evaluated the outcomes of patients with TBS and POBPF who were treated by placement of recent generation, fully covered, self-expanding metallic stents (SEMS) and determined stent efficacy relative to airway pathology.

Methods: From January 2009 to January 2016, 68 patients with TBS or POBPF underwent rigid bronchoscopy, laser/mechanical debridement and placement of fully covered SEMS. Eighteen patients had benign stenosis, 38 had malignant stenosis, and 12 patients had POBPF.

Results: Seventy-four SEMS were successfully placed in 68 patients. There were no perioperative deaths. Stent-related complications occurred in 20 (29.4\%) patients: granulation tissue formation [TBS group, $10.7 \%(n=6)$; POBPF group, $8.3 \%(n=1)$ ]; stent fracture [TBS group, 5.4\% ( $n=3)$; POBF group, $8.3 \%$ $(n=1)$ ], stent migration [TBS group, $7.1 \%(n=4)$; POBF group, $0 \%(n=0)$ ], severe secretions not removable by flexible bronchoscopy [TBS group, 7.1\% $(n=4)$; POBF group, $8.3 \%(n=1)$ ]. No stent migration was observed in the POBPF group. Four patients $(7.1 \%)$ in the TBS group had stent migration requiring stent replacement. After stenting, all TBS patients had a Hugh-Jones classification score improvement $\geq 1$ grade and 42 patients (75\%) had an improvement $\geq 2$ grades. Logistic regression analysis showed that the disease (stenosis vs. fistula) did not influence the occurrence of stent complications [OR 0.96, 95\% confidence interval (CI): 0.71-1.13, $\mathrm{P}=0.13$ ].

Conclusions: Fully covered SEMS are effective and provide a versatile treatment option for patients with inoperable TBS and POBPF.

Keywords: Tracheobronchial stenosis (TBS); postoperative bronchopleural fistula (POBPF); self-expanding metallic stents (SEMS); Nytinol

Submitted May 04, 2017. Accepted for publication Oct 23, 2017.

doi: $10.21037 /$ jtd.2017.10.139

View this article at: http://dx.doi.org/10.21037/jtd.2017.10.139

(c) Journal of Thoracic Disease. All rights reserved. 


\section{Introduction}

Endoscopic management of benign and malignant tracheobronchial disorders often requires the insertion of an airway stent. Several types of positionable stents are available (1). Silicone polymer stents (SPS) are widely used, less expensive, and easier to use and manage (2-4). However, SPS have structural limitations: poor adaptability to irregularly sized stenosis, imperfect adherence to airway mucosa, stent migration in patients with subglottic stenosis, in-stent granulation tissue formation, and secretion retention (5).

In 1999, Bollinger described a hypothetical future stent with metallic components and a synthetic coating of silicone or polyurethane as the "ideal stent" (5). The latest generation of self-expanding metal stents (SEMS) may meet this description. A third-generation coated SEMS such as the SILMET ${ }^{\circledR}$ (TRACHEOBRONXANE SILMET $^{\circledR}$, Novatech SA, La Ciotat, France) has a Nytinol (an alloy of nickel and titanium) structure coated with a thin synthetic layer of polyester material which provides resistance and minimal adhesion to the mucous membrane (6). Its selfexpanding ability creates a shape-memory effect, as it undergoes temperature-induced deformation and recovery of its original shape under normal human body temperature conditions (7). The polyester stent coating minimizes the risk of tissue ingrowth, which can occur in uncoated stents, and makes stent removal easier (7). Nytinol is biocompatible and highly resistant to corrosion; thus minimizing the risk of trauma. The mesh structure of Nytinol provides a high resistance against compression and ensures the maintenance of structure and function, even in the unlikely event of a broken wire (8). Compared to the early SPS, SEMS have thinner walls that allow more airflow and are designed to limit the complications that occur from in-stent granulomas (9). The aim of the study was to evaluate the outcomes of patients with tracheobronchial diseases treated by SEMS in order to examine the suitability of SEMS independent from the airway disorder classification.

\section{Methods}

\section{Patients and surgery}

From January 2009 to January 2016, n=68 patients with symptomatic benign or neoplastic tracheobronchial disorders underwent rigid bronchoscopy, endoscopic treatment, and airway stenting with coated SEMS (TRACHEOBRONXANE SILMET ${ }^{\circledR}$, Novatech SA, La Ciotat, France). For all patients enrolled in this retrospective study, surgical resection/reconstruction of the airway was considered not technically feasible or was contraindicated due to medical comorbidities. The Hospital Ethics Committee provided approval for the study (10830/2017) and an informed preoperative consent was obtained from all patients. Preoperative examination of all patients included clinical history, fiberoptic bronchoscopy, and high resolution CT scanning. Patients were divided into two groups: patients who underwent fully covered SEMS stenting either for a benign/malignant tracheal or bronchial stenosis (TBS group, $\mathrm{n}=56$ ) or for a postoperative (post pneumonectomy, lobectomy, or sleeve lobectomy) bronchopleural fistula (POBPF group, $\mathrm{n}=12$ ).

Freitag's classification (10) was used to describe and classify the type of stenosis in the TBS group. A numeric code was assigned to the specific degree of stenosis: from G1 ( $<25 \%$ of a cross-sectional area of the airway obstruction) to G5 (complete airway obstruction). The Hugh-Jones test (11) was used to evaluate respiratory function pre- and post-stent implantation. All incidences of POBPF occurred between the $4^{\text {th }}$ and $14^{\text {th }}$ day after surgery. Fistula diameter was $\geq 5 \mathrm{~mm}$ in all patients (mean $10 \pm 2.4 \mathrm{~mm}$ ).

All stent implantations were performed via rigid bronchoscopy with Dumon's rigid bronchoscope (Efer Medical, Cedex, France) in deep sedation with shortacting narcotics and benzodiazepines, independently breathing during all procedures. Flexible bronchoscopy was performed in all patients at 10 days and 1 month, 3 , and 6 months postoperatively. Subsequent bronchoscopic examinations were performed on a case by case basis. Stent position, secretion plugs, granulation tissue formation at stent margins, stent fracture, and capacity to adhere to the airway mucosa were evaluated. A numeric scoring system to evaluate the secretion plugs was introduced for the first time, with a numeric value assigned to each patient depending on the severity of secretion retention: 0 (no secretions), 1 (moderate secretions easily removable with flexible bronchoscopy), 2 (severe secretions not removable with flexible bronchoscopy, necessitating stent removal). To assess the capacity of the SEMS to adhere to the airway mucosa and to adjust to irregularly sized stenosis, stent migration was evaluated for both groups. Air leak occurrence after stent placement was evaluated and scored for the POBPF group: 0 (no air leaks), 1 (moderate air leaks), 2 (severe air leaks). The secretion score was assigned at the 1 month evaluation, while air leak occurrence was evaluated immediately after stent positioning via bronchoscopy and the chest tube. 

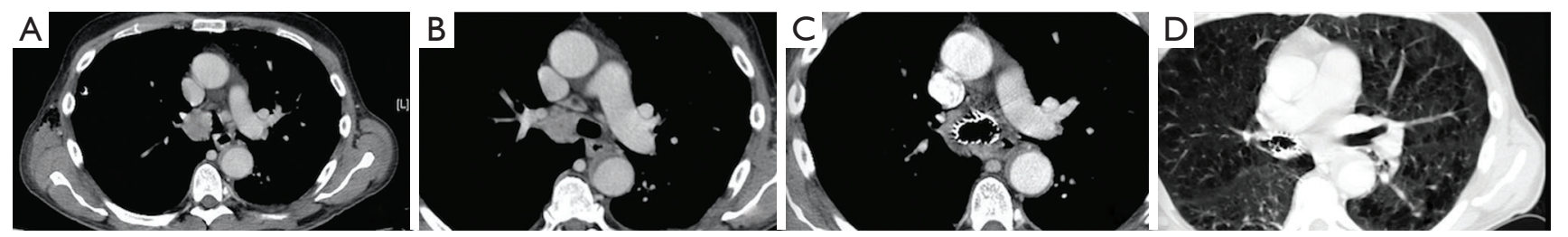

Figure 1 Treatment of malignant stenosis. (A,B). A computed tomography (CT) scan shows obstruction between the distal trachea and the right main bronchus; (C) CT images show the endotracheal stent at the level of the carina and the uncovered distal end of the stent in the intermediate bronchus allowing effective ventilation of the right upper lobe; (D) a custom-made, conical, partially coated, SEMS with a proximal diameter (tracheal) of $22 \mathrm{~mm}$, a distal diameter (bronchial) of $16 \mathrm{~mm}$, a length of $60 \mathrm{~mm}$, and a distal portion of $2 \mathrm{~cm}$ with no coating, to prevent obstruction of the right upper lobe bronchus. SEMS, self-expanding metallic stents.
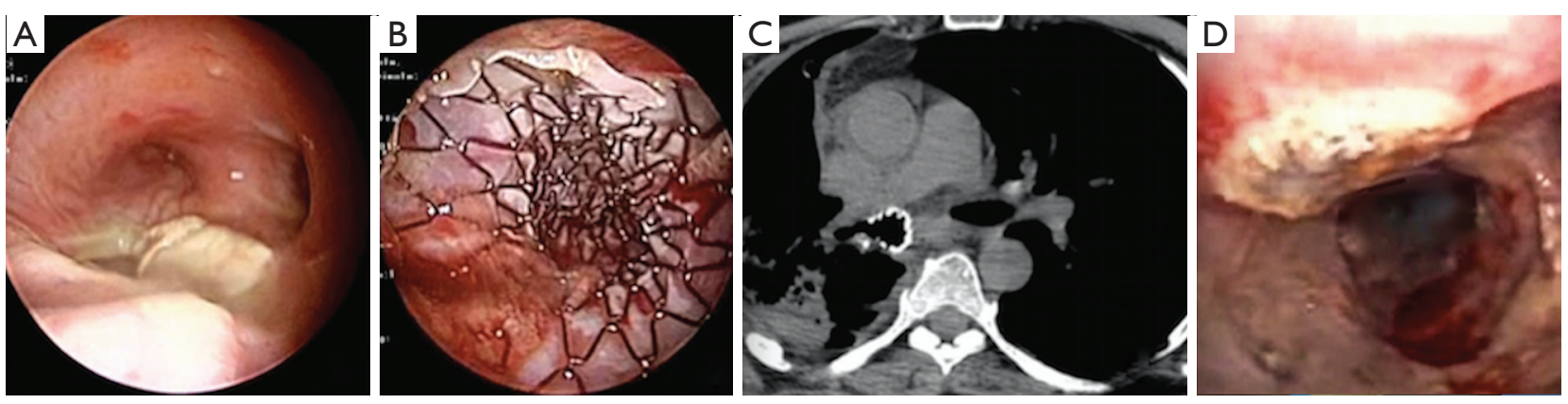

Figure 2 Management of postoperative bronchopleural fistula. (A) The endoscopic image shows a $3 \mathrm{~cm}$ ischemic lesion of the bronchial membranous pars after a bilobectomy (lower and middle lobe); (B) the image shows the total exclusion of the fistula by a conical 22-16-50 mm SILMET $^{\circledR}$ stent placement; (C) the CT scan image shows the hole made in the stent wall by ND:YAP laser ablation to allow the right upper lobe to ventilate; (D) the endoscopic image shows the complete closure of the membranous pars fistula after stent removal (4 months).

\section{Tracheobronchial stenosis (TBS) group}

In all TBS patients, airway patency was improved by mechanical dilatation first and/or application of neodymium-doped yttrium aluminum perovskite (ND:YAP) laser (Lokki Lis Laser, Bryan Corporation, Woburn, MA). In cases of restenosis from a benign obstruction, patients were treated with SEMS stenting only after a previous mechanical dilatation and laser treatment.

Patients with malignant stenosis were treated first by dilatation and then by airway stabilization with SEMS. Stent length was chosen in relation to the stenosis type (structural, functional, mixed) and shape (1). The stent length for structural stenosis was based on a $5-\mathrm{mm}$ free margin upstream and downstream from the stenosis. For mixed stenosis, stents of the same or longer length were used for stabilization of the malacic section.

For stenosis involving the distal trachea left or right lung ventilation was guaranteed by the removal of $1 \mathrm{~cm}^{2}$ of the polyester coating of the stent by ND:YAP laser. The absence of a coating layer in the terminal section of the stent $(20 \mathrm{~mm})$ allowed the right upper lobe bronchus to ventilate (Figure 1).

\section{Postoperative bronchopleural fistula (POBPF) group}

The type of stent used to exclude a POBPF from the airflow was conical and fully coated, with a proximal diameter (tracheal) of $22 \mathrm{~mm}$, a distal diameter (bronchial) of $16 \mathrm{~mm}$, and a length of $50 \mathrm{~mm}$ in all patients. Seven patients presented with POBPF occurring after right pneumonectomy $(n=6)$ and left pneumonectomy $(n=1)$. Two patients were treated for anastomotic dehiscence, one of which occurred after right tracheal sleeve pneumonectomy and one which occurred after left upper sleeve lobectomy. Two patients experienced a complete dehiscence of the bronchial stump after right upper lobectomy. One patient had a large lesion of the membranous pars of the bronchus intermedius after right bilobectomy (lower and medium lobectomy) (Figure 2). 


\section{Statistical analysis}

For the analysis of quantitative variables (normality of distribution verified by the Kolmogorov-Smirnov test), an unpaired t-test was used. Fisher's $t$-test was used to compare qualitative variables. The Mann-Whitney $U$ test was performed to compare Hugh-Jones scale scores for the two groups at 1 and 3 months, after controlling for preoperative variables. A logistic regression analysis was performed to evaluate potential risk or protective factors for stent complication occurrences, including stent migration, stent fracture, granulation tissue formation, and severe secretions not removable with flexible bronchoscopy (Secretion Scale =2). A significance level (alpha) of 0.05 was fixed.

\section{Results}

Characteristics of patients are shown in Table 1. Seventyfour self-expanding, coated, metallic SILMET ${ }^{\circledR}$ stents were successfully placed in 68 patients. Post-operative results are shown in Table 2. The mean patient age was $62.4 \pm 19.5$ years (range, 49-81 years). The cause of tracheobronchial obstruction was benign in 18 patients $(32.1 \%)$ [posttracheostomy, $22.2 \%(\mathrm{n}=4)$; post-intubation, $27.8 \%$ $(\mathrm{n}=5)$; post bronchial reconstruction, $16.7 \%(\mathrm{n}=3)$; post tuberculosis granulomas, $33.3 \%(\mathrm{n}=6)]$ and malignant in 38 patients $(67.9 \%)$ [non-small cell lung cancer, $41.1 \%$ $(\mathrm{n}=23)$; metastatic or locally advanced tumors from other organs, $26.8 \%(\mathrm{n}=15)$ : esophagus, $5.4 \%(\mathrm{n}=3)$; thyroid, $7.1 \%(n=4)$; metastatic colorectal, $8.9 \%(n=5)$, bladder, $1.8 \%$ $(\mathrm{n}=1)$, and kidney cancer, $3.6 \%(\mathrm{n}=2)]$. Twelve patients were affected by POBPF [post-pneumonectomy, 58.3\% (n=7); post right tracheal sleeve pneumonectomy, $8.3 \%(\mathrm{n}=1)$; post left upper sleeve lobectomy fistula, $8.3 \%(\mathrm{n}=1)$; postlobectomy, $16.7 \%(\mathrm{n}=2)$; post-bilobectomy, $8.3 \%(\mathrm{n}=1)]$.

The length of tracheal stenosis was 20 to $30 \mathrm{~mm}$ in 8 patients (38.1\%), 30 to $40 \mathrm{~mm}$ in 11 patients $(52.4 \%)$, and 40 to $50 \mathrm{~mm}$ in 2 patients (9.5\%). The length of bronchial stenosis was 20 to $30 \mathrm{~mm}$ in 25 patients $(71.4 \%)$ and 30 to $40 \mathrm{~mm}$ in 10 patients (28.6\%) (Figure 3).

No perioperative mortality was recorded. In all TBS group patients, a significant improvement in Hugh-Jones score was recorded at 1 month after stent implantation (Figure 4): all TBS patients had a Hugh-Jones classification score improvement $\geq 1$ grade and 42 patients $(75 \%)$ had an improvement $\geq 2$ grades $(\mathrm{P}=0.001)$ and only 14 patients (25\%) had an improvement of $<2$ grades at 1 month after stenting. However, a downgrading of the Hugh-Jones score was recorded at 3 months after stenting: 10 patients (17.9\%) decreased from grade 1 to grade $2(\mathrm{P}=0.07)$ and 19 patients (33.9\%) decreased from grade 1 to grade $3(\mathrm{P}=0.001)$.

Spontaneous stent migration occurred in 4 TBS group patients: 3 patients (5.4\%) with a tracheal stent on postoperative days (POD) 20, 40, and 55; and 1 patient (1.8\%) with a bronchial stent on POD 28. Only 3 patients (5.4\%) needed stent replacement with a larger SEMS. In 1 patient $(1.8 \%)$, the stent was not replaced because the stenosis had not recurred.

Six TBS group patients (10.7\%) and 1 POBPF patient (8.3\%) experienced granulation tissue formation ( $\mathrm{P}=0.809)$. None of the patients required stent removal or replacement. However, in 1 patient of TBS group (1.8\%) with benign post-intubation stenosis of the distal section of the trachea, granulation tissue was found at the proximal edge of the stent. In that patient, two weeks after the first stenting, a telescope shaped SPS was placed inside the SEMS to cover the granulation tissue at the proximal edge of the stent.

Four $(7.1 \%)$ TBS group patients needed stent removal and replacement due to stent fracture/migration or because of a Secretion Scale $=2(\mathrm{SS} 2): 1$ patient had a SS2 and a stent fracture; 1 patient had a SS2; 1 patient had a SS2, a stent fracture, and later stent migration. In 1 patient who was treated for main left bronchus stenosis, removal of the stent was required after 4 weeks due to in-stent growth of a malignancy that displaced the stent by changing its structure and fracturing it. In that patient, a second lasermechanical dilatation and SPS stenting was performed. In 1 patient, stent replacement was unnecessary after migration of the stent due to the patient's recovery from the stenosis. In all but 6 TBS group patients (10.7\%), the stent could not be removed because of stenosis persistence. The permanent time of stent was $42 \pm 7$ months in TBS group.

In almost all POBF patients $(91.7 \%, \mathrm{n}=11)$ the stent was successfully removed and not replaced due to recovery from the fistula. In 10 patients (83.3\%), the SEMS was removed 4 months after stenting following negative bronchoscopic examination, a CT scan showing a resolution of the fistula, and negative inflammation blood tests (Figure 5). In 1 patient $(8.3 \%)$, the SEMS was removed because of a SS2.

In 12 POBF patients (100\%), immediate resolution of the air leaks was obtained. Permanent closure of bronchial dehiscence without recurrence was achieved in all the patients.

All patients from both groups underwent endoscopic evaluation at one month after stent placement to determine the Secretion Scale. No statistically significant differences 
Table 1 Characteristics of patients

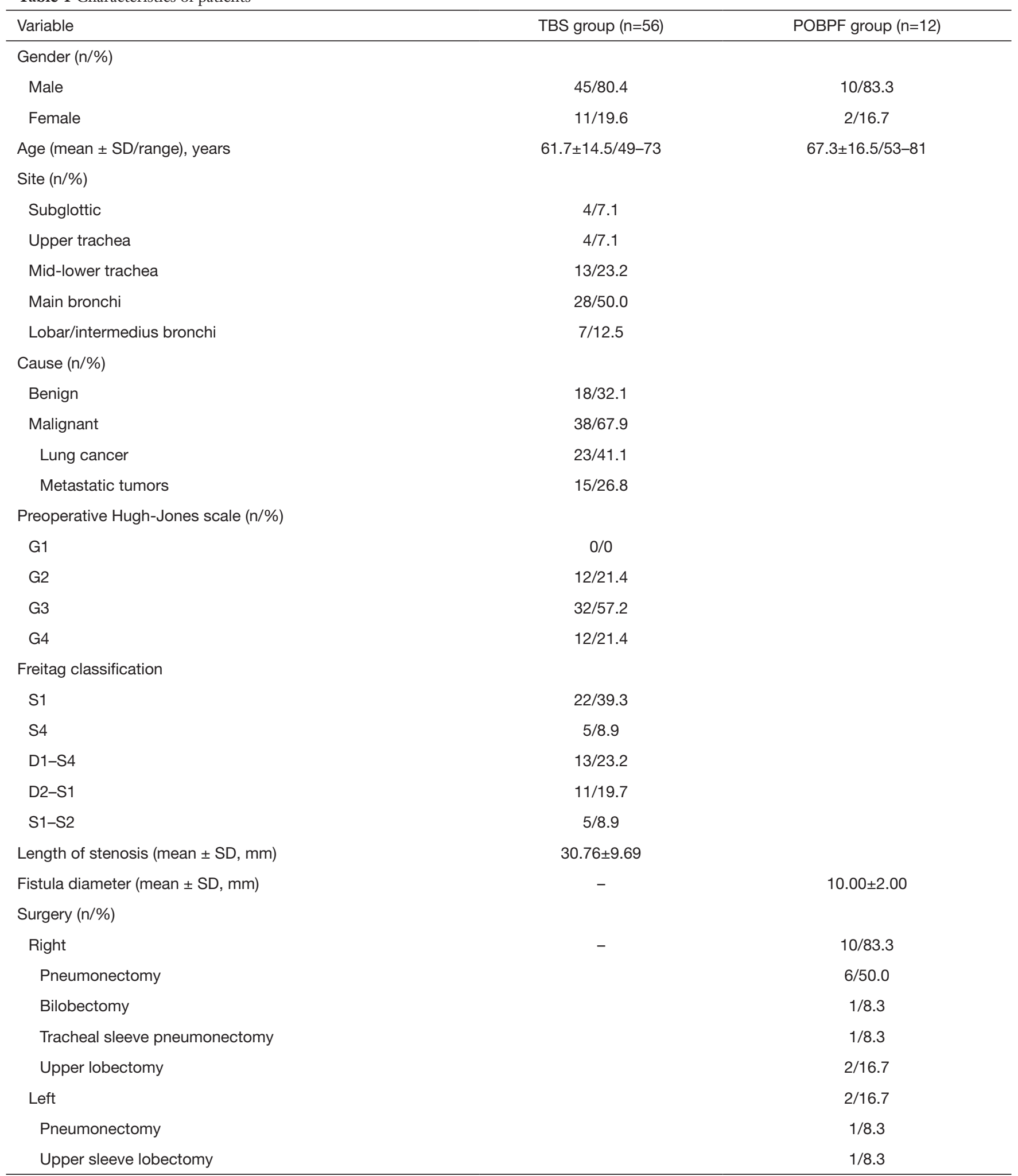

TBS, tracheobronchial stenosis; POBPF, postoperative bronchopleural fistulas; SD, standard deviation. 
Table 2 Results

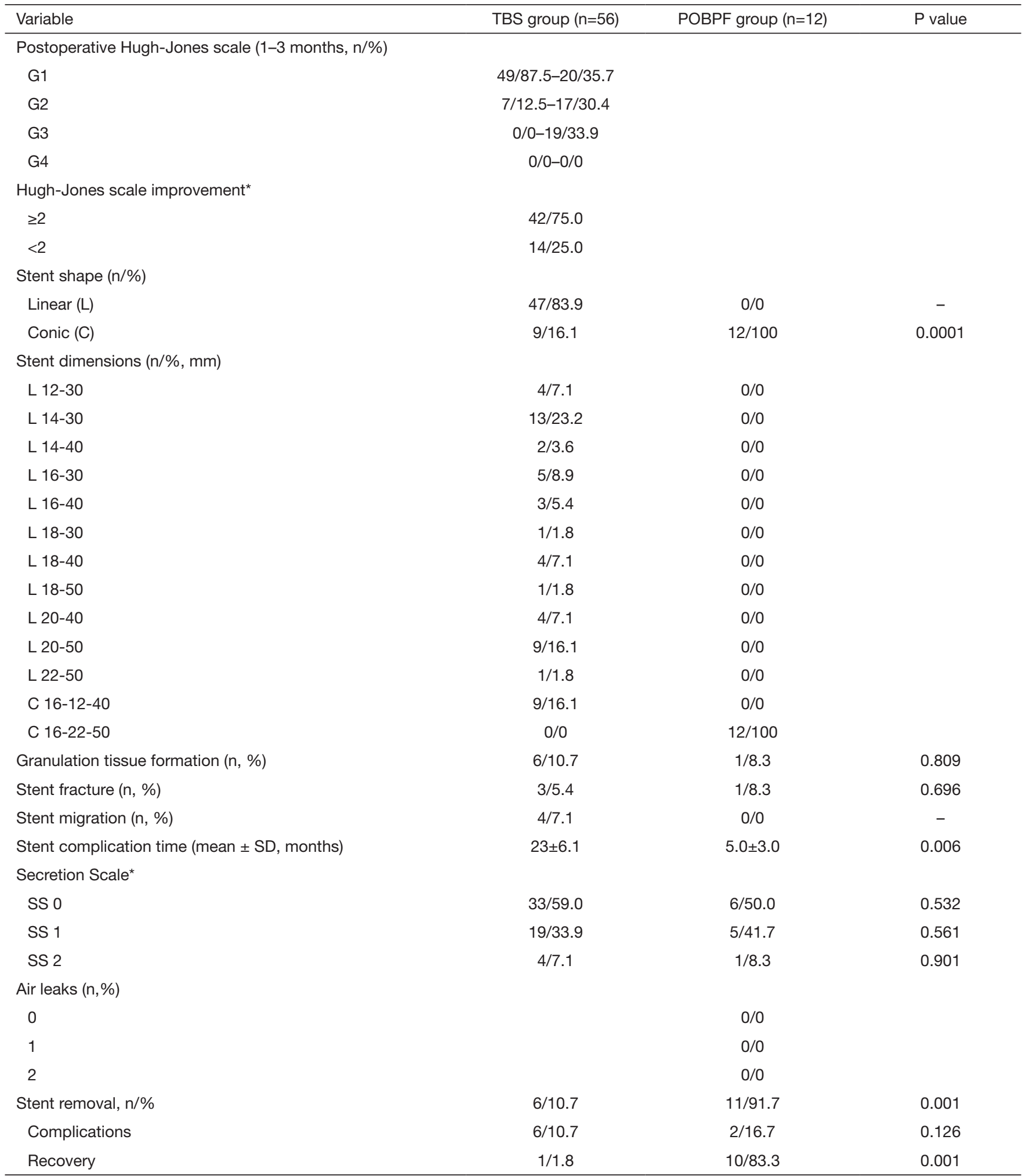

*, at 1 month after surgery. SS: 0 (no secretions), 1 (moderate secretions easily removable with flexible bronchoscopy), 2 (severe secretions non-removable with flexible bronchoscopy, necessary stent removal). TBS, tracheobronchial stenosis; POBPF, postoperative bronchopleural fistulas; SD, standard deviation. 


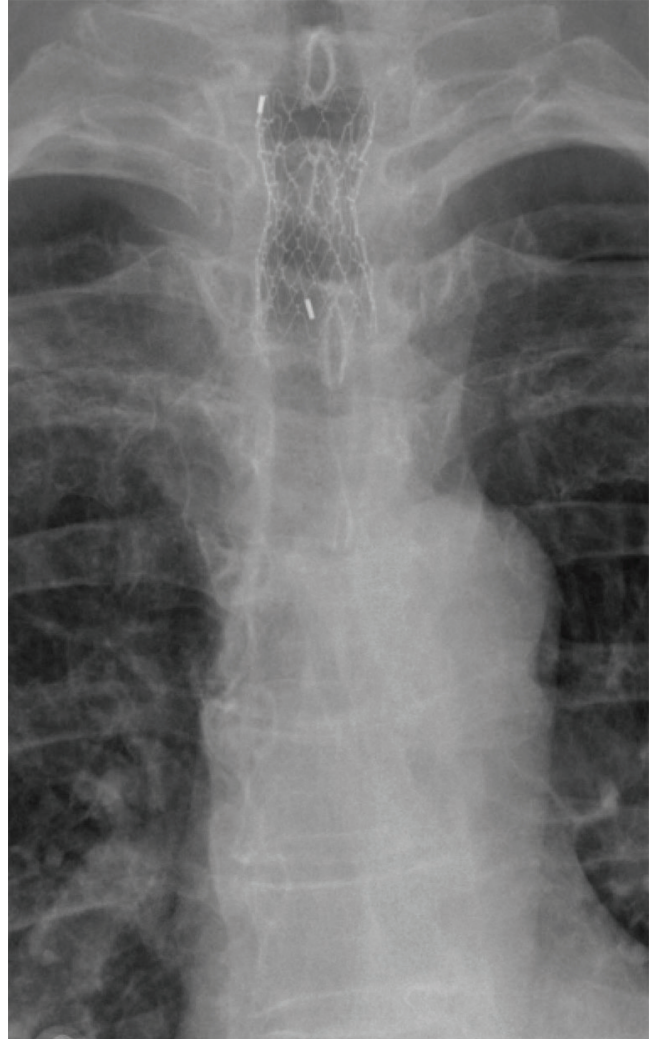

Figure 3 A chest $\mathrm{X}$-ray taken at $24 \mathrm{~h}$ after dilatation and a 20-40 mm linear SILMET ${ }^{\circledR}$ stent placement in a patient with a $2 \mathrm{~cm}$ mixed stenosis of the upper third of the trachea.

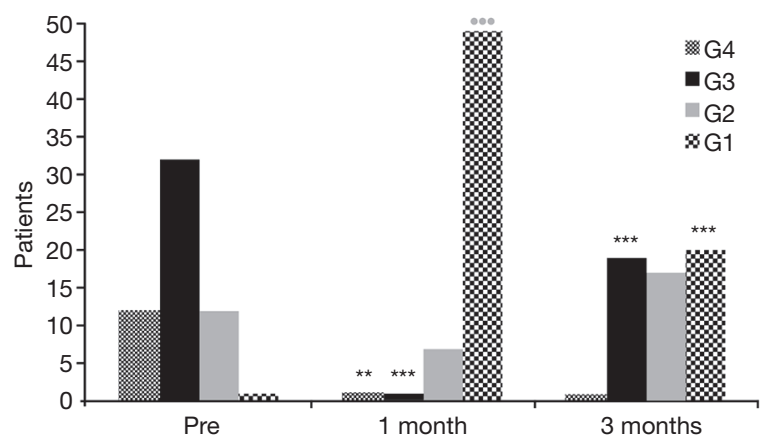

Figure 4 Hugh-Jones scores in patients with tracheobronchial stenosis (TBS group): preoperative and postoperative values after 1 and 3 months after stenting. ${ }^{* *}, \mathrm{P}=0.001 ;{ }^{* * *}, \mathrm{P}=0.0001$.

were shown between the groups for SS0, SS1, and SS2 $(\mathrm{P}=0.532, \mathrm{P}=0.561$, and $\mathrm{P}=0.901$, respectively).

Mean time for stent complications was $23 \pm 6.1$ months in the TBS group and 5.0 \pm 3.0 months in the POBPF group with a statistically significant difference $(\mathrm{P}=0.006)$.
However, logistic regression analysis showed that stent complication occurrences, including stent migration, stent fracture, granulation tissue formation, and severe secretions not removable with flexible bronchoscopy (SS2), were independent from the type of airway disorder [OR $=0.96, \mathrm{P}=0.13,95 \%$ confidence interval $(\mathrm{CI}): 0.71-1.13]$ and patient gender $(\mathrm{OR}=0.81, \mathrm{P}=0.54,95 \% \mathrm{CI}$ : $0.45-1.31)$; but did seem to be influenced by age $>70$ years $(\mathrm{OR}=0.21$, $\mathrm{P}=0.01,95 \%$ CI: 0.21-0.76) (Table 3).

\section{Discussion}

Inoperable tracheobronchial disorders caused by benign/ malignant stenosis or complications occurring after major lung resection, in particular POBPF, represent a significant clinical problem $(12,13)$. Surgical resection represents the gold standard for benign tracheal strictures (14). SPS have been used extensively for their ability to be easily removed and repositioned. However, a major disadvantage of SPS is secretion retention in the lumen caused by interference on the physiological mucociliary function of the tracheobronchial epithelium that was interrupted by the stent (15). In addition, SPS are poorly tolerated at the subglottis level and are likely to migrate when used to treat complex tracheal strictures (15). Self-expandable stents were introduced in the 1980s to solve these problems. Although they can be easily inserted via flexible bronchoscopy, tumor or granulation tissue ingrowth around the stent and epithelialization into the airway wall make their removal challenging (16). In 2004, Wood discussed eight fundamental points that a tracheobronchial stent should have. In particular, he stressed the importance of ease of use and the ability to conform to airway contours to guarantee good airway clearance (17).

Several structural limitations due to the use of SPS construction were experienced: poor adaptability to irregularly sized stenosis, insufficient adherence to the airway mucosa, high percentage of stent migration in patients with subglottic stenosis, in-stent granulation tissue formation, and secretion retention. Moreover, many patients underwent stent repositioning for severe secretion retention due to the inability to clear the stent with flexible bronchoscopy. A high incidence of stent migration in cases of subglottic stenosis, irregular stenosis, and complex stenosis (D1-S4) occurred.

In the present study, SEMS exhibited a high tolerance level when in contact with bronchial mucosa in a majority of the patients $(92.6 \%)$. Improvement of symptoms was 

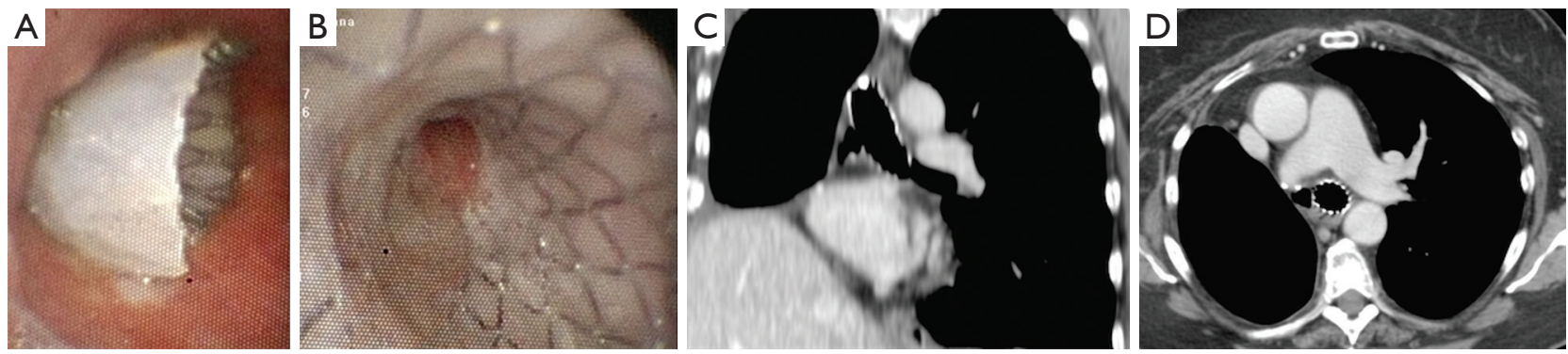

Figure 5 Treatment of post-pneumonectomy bronchopleural fistula. (A,B) CT scan images show endoscopic control 2 months after the placement of a conical SILMET ${ }^{\circledR}$ stent (size 22-16-50) in a patient with POBPF after right pneumonectomy; (C,D) complete exclusion of the fistula from the tracheobronchial system. POBPF, postoperative bronchopleural fistulas.

Table 3 Logistic regression analysis of stent complications (stent migration, stent fracture, granulation tissue formation, severe secretions non-removable with flexible bronchoscopy)

\begin{tabular}{lccc}
\hline Variables & OR & P value & $95 \% \mathrm{Cl}$ \\
\hline Age (>70 vs. $\leq 70$ years) & 0.21 & 0.01 & $0.21-0.76$ \\
Gender (male vs. female) & 0.81 & 0.54 & $0.45-1.31$ \\
Disease (stenosis vs. fistula) & 0.96 & 0.13 & $0.71-1.13$ \\
\hline
\end{tabular}

OR, odds ratio; $\mathrm{Cl}$, confidence interval.

obtained in $100 \%$ of treated patients. Hugh-Jones scores improved in all TBS group patients at 1 month after stenting. However, as shown in Figure 4, 51.8\% of TBS group patients experienced a worsening of the Hugh-Jones score at 3 months after stenting. This may be due to a patient perception of a lack of further improvement, based on reports from the majority of patients. In-stent granuloma formation was relatively infrequent (10.3\%). A major SEMS disadvantage is stent collapse due to Nytinol structural alteration. Stent fracture or stent migration occurred in only $5.9 \%$ of all patients in the present study.

In the present study (68 cases), SEMS use produced excellent results in the treatment of stenosis of the upper third of the trachea after tracheotomy. The SILMET ${ }^{\circledR}$ stent adhered to the tracheal wall well enough to reduce the risk of migration significantly, a frequent phenomenon in the treatment of subglottic stenosis with polymeric implants. In addition, the availability of different stent sizes made them extremely versatile in comparison with Dumon stents, particularly in irregularly sized stenosis.

For treatment of tracheobronchial stenosis, it is essential to choose the correct stent length to avoid stent migration and consequent obstruction of the distal airway ventilation.
In addition, a stent that is too long can damage normal distal airway mucosa. Based on our experience, a good selection criteria is to choose a stent length at least $1 \mathrm{~cm}$ longer than the stenosis length (18). In the present study, only $7.1 \%$ of all patients experienced stent migration and $10.7 \%$ of all patients developed granulation tissue formation. In the TBS group, the stent was removed only in the event of stent fracture, stent migration, or the presence of severe secretions not removable with flexible bronchoscopy (SS2). The stent was removed in only 1 patient due to recovery from the stenosis. In all the other patients, stent removal was not possible for malignant or benign stenosis. This results can be explained considering the significant number of patients affected by malignant disease in our TBS population, which rarely achieve a successful decannulation. Terra and colleague reported in an exclusive benign tracheal stenosis population, an estimate successful decannulation rate of $27.5 \%$ (19). In our center the stent usually remain in place at list 36 months. In this series the permanent time of stent was $42 \pm 7$ months in TBS group. In the POBPF group, almost all SEMS (91.7\%) were removed after fistula resolution.

POBPF is the most serious complication experienced by the thoracic surgeon (13). Differing local treatments and stenting were proposed for rapid treatment of this emergent complication. As previously reported by Andreetti et al. (20), the positioning of SEMS in patients with POBPF often requires the use of a laser to partially ablate the stent polyester cover to allow upper lobe ventilation. The procedure did not damage the Nytinol support and left it intact without decreasing stent strength.

For the treatment of POBPF in the present study, a standard size, conical, coated, self-expandable SILMET ${ }^{\circledR}$ stent (proximal diameter $=22 \mathrm{~mm}$, distal diameter $=16 \mathrm{~mm}$, 
and length $=50 \mathrm{~mm}$ ) was generally used. It provided the highest level of adaptability in all types of fistula and has been described as the "life-saving stent" (20). The use of a standard size stent allowed quick treatment of the complication, without the wait of at least 3 weeks (estimated time by the manufacturer) to build a custom made stent. For this reason a "life-saving stent" should always be available in a high volume Thoracic Surgery Department.

Importantly, the versatility of SEMS is demonstrated in the present study. Stent complication occurrence, including stent migration, stent fracture, granulation tissue formation, and severe secretions not removable with flexible bronchoscopy (SS2), was independent from the type of airway disorder $(\mathrm{OR}=0.96, \mathrm{P}=0.13,95 \% \mathrm{CI}=0.71-1.13)$, based on our logistic regression analysis.

Conversely, SEMS, compared with the SPS, presented some limitations, such as a higher cost and the inability to reload the stent in the delivery catheter after an incorrect implantation. The stent position can be adjusted only by moving it upward or downward with the use of a clamp.

In conclusion, a coated SEMS implant is an effective and versatile treatment for patients affected by irregularly sized TBS and POBPF. Its versatility is independent from the airway disorder.

\section{Acknowledgements}

The authors acknowledge Dr. Marta Silvi, Data Manager, Division of Thoracic Surgery, Sant'Andrea Hospital, Faculty of Medicine and Psychology, University of Rome "Sapienza", and Matteo Sala for Figures editing.

\section{Footnote}

Conflicts of Interest: The authors have no conflicts of interest to declare.

Ethical Statement: The Hospital Ethics Committee provided approval for the study (10830/2017) and an informed preoperative consent was obtained from all patients.

\section{References}

1. Lee P, Kupeli E, Mehta AC. Airway stents. Clin Chest Med 2010;31:141-50, Table of Contents.

2. Furukawa K, Ishida J, Yamaguchi G, et al. The role of airway stent placement in the management of tracheobronchial stenosis caused by inoperable advanced lung cancer. Surg Today 2010;40:315-20.

3. Casal RF. Update in airway stents. Curr Opin Pulm Med 2010;16:321-8.

4. Bolliger CT, Probst R, Tschopp K, et al. Silicone stents in the management of inoperable tracheobronchial stenoses. Indications and limitations. Chest 1993;104:1653-9.

5. Bolliger CT. [Prosthesis: indications, contraindications and follow-up]. Rev Mal Respir 1999;16:665-72.

6. Vinograd I, Klin B, Brosh T, et al. A new intratracheal stent made from nitinol, an alloy with "shape memory effect". J Thorac Cardiovasc Surg 1994;107:1255-61.

7. Marchese R, Poidomani G, Paglino G, et al. Fully covered self-expandable metal stent in tracheobronchial disorders: clinical experience. Respiration 2015;89:49-56.

8. Nesbitt JC, Carrasco H. Expandable stents. Chest Surg Clin N Am 1996;6:305-28.

9. Lehman JD, Gordon RL, Kerlan RK Jr, et al. Expandable metallic stents in benign tracheobronchial obstruction. J Thorac Imaging 1998;13:105-15.

10. Freitag L, Ernst A, Unger M, et al. A proposed classification system of central airway stenosis. Eur Respir J 2007;30:7-12.

11. Hugh-Jones P, Lambert AV. A simple standard exercise test and its use for measuring exertion dyspnoea. Br Med J 1952;1:65-71.

12. Le Brigand $\mathrm{H}$. Fistules bronchiques après pneumonectomies. In: Le Brigand H. editor. Appareil respiratoire, mediastin, paroi thoracique. Paris: $\mathrm{Ed}$ Masson, 1973:462-70.

13. Hollaus PH, Lax F, el-Nashef BB, et al. Natural history of bronchopleural fistula after pneumonectomy: a review of 96 cases. Ann Thorac Surg 1997;63:1391-6; discussion 1396-7.

14. Grillo HC, Donahue DM. Postintubation tracheal stenosis. Chest Surg Clin N Am 1996;6:725-31.

15. Lemaire A, Burfeind WR, Toloza E, et al. Outcomes of tracheobronchial stents in patients with malignant airway disease. Ann Thorac Surg 2005;80:434-7; discussion 437-8.

16. Gaissert HA, Grillo HC, Wright CD, et al. Complication of benign tracheobronchial strictures by self-expanding metal stents. J Thorac Cardiovasc Surg 2003;126:744-7.

17. Wood DE. Tracheal and bronchial stenting. In: Grillo HC. editor. Surgery of the Trachea and Bronchi. Hamilton: BC Decker, 2004:765-90.

18. Andreetti C, D'Andrilli A, Ibrahim M, et al. Treatment of a complex tracheobronchial malignant stenosis with a modified conical semicovered self-expanding stent. J 
Thorac Cardiovasc Surg 2013;146:488-9.

19. Terra RM, Bibas BJ, Minamoto H, et al. Decannulation in tracheal stenosis deemed inoperable is possible after longterm airway stenting. Ann Thorac Surg 2013;95:440-4.

Cite this article as: Menna C, Poggi C, Ibrahim M, D’Andrilli A, Ciccone AM, Maurizi G, Cassiano F, Baccarini AE, Massullo D, Venuta F, Rendina EA, Andreetti C. Coated expandable metal stents are effective irrespective of airway pathology. J Thorac Dis 2017;9(11):4574-4583. doi: 10.21037/ jtd.2017.10.139
20. Andreetti C, D'Andrilli A, Ibrahim M, et al. Effective treatment of post-pneumonectomy bronchopleural fistula by conical fully covered self-expandable stent. Interact Cardiovasc Thorac Surg 2012;14:420-3. 